\title{
PROCESS AMBIDEXTERITY IN STARTUPS INNOVATION
}

\author{
Jarosław KORPYSA \\ University of Szczecin
}

\begin{abstract}
:
The article is of theoretical and empirical character. The main objective is to identify certain conditions related to the innovative ambidexterity of Polish startups. The objective implementation protocol of the study determined its structure. Its first part presents the most important theoretical concepts related to the presented issues. In particular, on the basis of the literature on the subject, analyses of the innovative ambidexterity. Moreover a start-up was equated with a company operating no longer than a year, which offers an innovative solution. Theoretical considerations provided the basis for the empirical presentation of the results of the author's own research conducted in 2019 in Poland on startups. On the basis of the outcome it has been established the most important factors determining innovative ambidexterity in startups are: having access to external source of financing and to external infrastructure as well as the acquisition of a license/patent. Moreover it has been diagnosed that create innovation and simultaneously reduce in startups the tension between exploitation and exploration activities to a large extent rely on external sources when implementing their innovation processes. For the theory on management, the theoretical-empirical deliberations presented in the article may be a valuable source of information within the scope of the influence the particular elements of innovative ambidexterity have on startups. However, for entrepreneurs they may be an impulse in the field of effective use of the innovative ambidexterity in the process of building competitiveness of young companies in Poland.
\end{abstract}

Key words: ambidexterity, innovation, startups, exploration and exploitation activities

\section{INTRODUCTION}

Modern processes of technical and technological progress, the intensity of competition, the increase in the importance of knowledge as well as intangible sources of generating the value of enterprises, all condition the need for simultaneous balancing of exploration and exploitation activities focused on creating innovations by startups [21]. At this point it should be borne in mind that innovative exploration and exploitation are contradictory, although not exclusive, processes that take place in the organization $[6,8,18,32]$. These processes are most often understood as orthogonal activity, which determines not only the survival of the startup but also its creation and advancement of innovation. In this respect, innovative exploration is reflected in the creation of radical innovations [13]. On the other hand, processes related to innovative exploitation are most often related to the creation of socalled incremental innovations, the aim of which is to maintain the existing effectiveness and competitiveness of companies by introducing small changes in the scope of offered products/services or existing technological processes [17]. It is worth noting in this respect that for startups the operational implications of innovation are burdened with much less risk and uncertainty than it is the case with innovative exploration. However, incremental innovations pose greater threat of slowing down the company development and reducing its profits than in the case of innovative exploration. Thus, the paradox of exploration and exploitation oriented operations forces startups to strive for an adaptive search for an ideal balance between the coexistent activities conditioning the simultaneous creation of incremental and radical innovations in the organization. This ability is defined as organizational ambidexterity [11] that determines the reconciliation of adaptive abilities related to innovation and to anticipatory changes [33].

This study aims to identify certain conditions related to the innovative ambidexterity of Polish startups. In the first part, which is based on the analysis and critical review of literature, the most important issues of the innovative ambidexterity are presented. Theoretical considerations are followed by the presentation of selected results of the research into the innovative ambidexterity of startups. In the summary, the main conclusions and guidelines for further scientific research are presented.

\section{AMBIDEXTERITY AND INNOVATION}

The concept of ambidexterity in innovation refers to balancing exploration and exploitation activities that determine the creation and development of innovation in an 
organization. Exploratory activities are aimed at creating so-called radical innovations. Such innovations require organizations to discover new knowledge and take significant risks in the process of discovering previously unknown opportunities. Thus, the process of creating radical innovations is focused on a longer time horizon than in the case of creating incremental innovations. What is more, this process is connected with significant financial outlays, engagement of new employees, increased flexibility or structural transformations of the organization [8]. On the other hand, exploitation activities, which are the basis for the creating incremental innovations by companies, are characterized by a low risk and provide organizations with additional opportunities for innovation development in a short period of time [25]. Such innovations are primarily reflected in the improvement of existing innovations through better and more efficient satisfaction of current customer needs or processes inside the organization. Therefore, incremental innovations require a company to exploit its knowledge. In contrast to radical innovations, the process of creating incremental innovations does not require significant financial outlays or large structural transformations of the organization. In addition, exploitation-oriented innovations rely more on open knowledge, continuity and repetition of tasks, making the results more reliable and less risky than radical innovations.

As far as research on innovative exploration and exploitation is concerned, it should be noted that part of researchers points to a negative correlation between radical and incremental innovations [21]. In this respect, researchers argue that organizations creating radical innovations always create them at the cost of abandoning incremental innovations. As Cooccia points out, a company always incurs significant costs of experimenting, which means that it lacks time, competence, people and money to develop innovation to improve [8]. However, when creating incremental innovations, the organization may abandon creating and acquiring new knowledge necessary to create radical innovations. Such behavior can most often be a result of successful incremental innovation, which directly determines the increase in the cost of alternative creation of radical innovation.

There are also studies in the literature in which scientists do not find correlations between these variables [14]. The lack of this correlation is justified by the fact that activities oriented at radical and incremental innovation are independent of each other [15]. In this trend, researchers point out that both types of innovation are to a large extent conditioned by diverse factors, which, as a consequence, contributes to a significant lack of interdependence between the variables.

However, the vast majority of modern studies confirm the mutual associations between exploration and exploitation [1]. In this way, researchers point to the existence of an orthogonal and multilayered relationship that implies the possibility for innovative exploration and exploitation to coexist in an organization [24]. In literature, this interdependence is referred to as the concept of innovative ambidexterity, and an organization that employs this concept - as a paradox lens. At this point it should be borne in mind that, thanks to the recognition of its competences, the paradox lens entity can use them to identify new opportunities for creating new products/services, technologies or functional processes [29].

It should be noted that ambidexterity in literature is perceived in three dimensions: structural ambidexterity, contextual ambidexterity and leadership ambidexterity [20]. In the former dimension, it is recommended to separate organizational exploration and exploitation. In this approach, radical and incremental innovations are created by separate teams that should be integrated at the highest level of management through coordinating managerial activities and knowledge integration systems [7].

The second type of ambidexterity concerns the behavioral abilities of the people employed in the organization. According to the concept of contextual ambidexterity, the balance between radical and incremental innovations depends on the company's staff and, in particular, on their ability to autonomously generate the balance between innovative exploration and exploitation [11, 15]. This balance is achieved by ensuring substantive support for the staff regarding task implementation and strengthening of the organizational culture based on mutual trust, delegation of tasks and respect for principles [32].

The final dimension of ambidexterity is leadership ambidexterity. It applies to top management who should make their managerial decisions having in mind the need to maintain the organizational ambidexterity in the process of creating innovations [2]. In this case, the leaders' cognitive skills are important who are guided by the need to balance exploration and exploitation when making innovation-driven decisions [14, 20].

Taking into account the above dimensions of ambidexterity, both structural, contextual and leadership, in the process of creating and developing innovations in the organization are complementary and coherent, as they stem from the organizational structure and entrepreneurial processes in the company [18, March 1991]. It should be noted here that many studies on ambidexterity focus on large organizations. This is due in particular to the fact that, according to the researchers, ambidexterity requires most organizations to have eclectic organizational structures which, on the one hand, ensure high efficiency in implementing current tasks aimed at creating operational innovations and, on the other, are geared towards producing incremental innovations. Thus, a combination of such contradictory measures is only possible in large companies with significant intellectual, financial and organizational capacity [27]. However, there are some studies dealing with ambidexterity in young startups. Researchers explaining the essence of ambidexterity in startups argue that due to hyper-competitive environment and pressure to increase sales, startups must not only create incremental but also radical innovations [26]. What is more, they indicate that exploration and exploitation activities not only positively condition the process of creating inno- 
vations in young enterprises, but also ensure their productivity growth [6]. In addition, ambidexterity also contributes to finding a repeatable and scalable business model that, according to Blank and Dorf, is the core of every startup [5]. At this point it should be noted that the innovative ambidexterity in startups also determines the development of new solutions, which, according to Reis, are an inherent attribute of startups [32]. Interestingly, Mueller, Volery, and von Siemens emphasize that exploration and exploitation activities in startups are aimed at taking advantage of the so-called entrepreneurial opportunity, which is fundamental for the businesses to function in the market environment [12].

Considering the above arguments and also taking into account such attributes of startups as:

- short period of presence on the market - most definitions quote a period of up to three years [28],

- creation of innovations, including disruptive innovations, which are characterized by hyperscalability, i.e. extremely fast growth in sales and/or the number of users leading ultimately to an increase in the company's value [30],

- recognizing and seizing market opportunities regardless of the available resources [31],

- operating in conditions of increased uncertainty and unpredictability of the environment in comparison to older enterprises [5].

Startups should look for ways to mitigate the effects of changes in the environment, to ensure stable operation and rapid growth in the market. This can be achieved through the innovative ambidexterity which is reflected in exploitative and exploratory innovations $[10,18]$. Moreover take into consideration differences in definition startups, in article startups has been equated with a company operating no longer than a year, which offers an innovative solution.

According to the author's knowledge, there is still a research gap regarding the analysis of innovative ambidexterity of startups in Poland. Therefore, the following part of the paper will be devoted to presenting selected empirical findings of the research into the issues discussed above.

\section{METHODOLOGY}

The research procedure was carried out in three stages. In the first stage, on the grounds of literature review a cognitive gap was identified, being the failure to recognize the conditions for innovative ambidexterity in Polish startups. In the second stage, research methods and tools necessary to carry out appropriate research were selected. At that stage the author decided that the empirical research will cover startups, i.e. enterprises that, according to the definitions given in the theoretical considerations above, operate on the market for a maximum of three years and create and offer innovative products to the market. Moreover, the geographical scope of the research will be limited to the region of Western Pomerania. The geographical scope of the research was chosen due to the author's cooperation with local startups and because there was no available public databases about young companies operating in Poland and in the West Pomeranian voivodeship in particular. Therefore, due to difficulties in contacting startups and in order to economize the research process, the author decided to limit the research area to Western Pomerania. The research was conducted in the second half of 2019.

With respect to the analyzed population, in his adopted empirical research approach the author used incomplete enumerative induction. Thereby, for the study of cause and effect relationships occurring in startups, he decided to use mainly the nomothetical approach.

The study applied the author's unique online questionnaire, which consisted of 18 survey questions, metric and diagnostic questions. At this point it should be borne in mind that an important role in determining the character of the surveyed companies was played by diagnostic questions. These questions had been created on the basis of the adopted definition of a startup, which is described in the theoretical part of this paper.

Using the simple random sampling procedure, the random sampling method and the stratified sampling method were applied to select 1200 companies from the Regon database. The companies were invited to participate in the research by e-mail. Finally, 43 startups were diagnosed in the course of a quantitative study.

Basing on the collected primary data, the empirical material was examined. In order to determine correlations between variables determining the process of establishment and performance of the subjects under study, the author applied chi square independence tests and the MannWhitney U test.

While empirically verifying the results, the reliability of the measurement was first checked with the use of Cronbach's alpha coefficient. On the basis of the data obtained, it should be stated that Cronbach's alpha coefficient for the whole integrated questionnaire was above 0.86 , which proves the high reliability of the conducted research. Moreover, when analyzing the individual components of the questionnaire referring to innovative ambidexterity in the companies under survey, it is clear that all the selected factors were characterized by reliability higher than the required minimum.

\section{RESEARCH RESULTS}

The characteristics of the surveyed companies clearly shows that the majority (62\%) of startups survived on the market for a maximum of 2 years, and $8 \%$ of them lasted less than 12 months. The remaining part (30\%) operated on the market longer than 2 years. It is also worth noting that dominating types of business activity were services $(58 \%)$ and trade (32\%). Less than every tenth startup reported production as their type of activity. As regards the legal form of business, $71 \%$ of entities operated as a sole proprietorship, $22 \%$ as a limited liability company and $7 \%$ as a civil law partnership. The last criterion for the classifying the surveyed population was the startup's geographical area of operation. The startups were classified as op- 
erating on international (43\%) and domestic (37\%) markets. The lowest number operated on local (6\%) and regional (14\%) markets.

Taking into consideration the purpose of the survey, the respondents were asked to express their opinions on a seven-point Likert scale, where 1 indicated strong disagreement and 7 indicated strong agreement. Detailed survey results are presented in the table below.

Table 1

Drivers of innovative ambidexterity

\begin{tabular}{lcccc}
\hline Drivers & $\mathbf{X}$ & $\mathbf{M e}$ & $\mathrm{Sd}$ & $\mathrm{Qr}$ \\
\hline $\begin{array}{l}\text { Innovative exploration through employee } \\
\text { training }\end{array}$ & 3.2 & 4 & 0.9 & 1 \\
$\begin{array}{l}\text { Innovative exploitation through employee } \\
\text { training }\end{array}$ & 4.8 & 4 & 1.0 & 2 \\
$\begin{array}{l}\text { Innovative exploration through leadership } \\
\text { in organization }\end{array}$ & 4.3 & 4 & 0.8 & 2 \\
$\begin{array}{l}\text { Innovative exploitation through leadership } \\
\text { in organization }\end{array}$ & 2.9 & 3 & 0.0 & 1 \\
$\begin{array}{l}\text { Innovative exploration through attending } \\
\text { trade fairs and direct contacts }\end{array}$ & 3.4 & 3 & 0.7 & 2
\end{tabular}

with customers

Innovative exploitation through attending

trade fairs and direct contacts

with customers

Innovative exploration through ensuring

own financial capital

Innovative exploitation through ensuring

own financial capital

Innovative exploration through financing

related activities from external sources

Innovative exploitation through financing

related activities from external sources

Innovative exploration through ensuring

own infrastructure (incl. machinery,

equipment)

Innovative exploitation through ensuring

own infrastructure (incl. machinery,

equipment)

Innovative exploration through purchase

of patent/license

Innovative exploitation through purchase

of patent/license

$\begin{array}{llll}4.0 & 4 & 0.6 & 2\end{array}$

$\begin{array}{llll}4.2 & 4 & 0.6 & 1\end{array}$

$\begin{array}{llll}4.8 & 5 & 0.7 & 1\end{array}$

$\begin{array}{llll}2.4 & 3 & 0.8 & 1\end{array}$

$\begin{array}{llll}3.2 & 2 & 0.8 & 2\end{array}$

$\begin{array}{llll}3.9 & 4 & 0.9 & 1\end{array}$

$\begin{array}{llll}3.6 & 4 & 1.1 & 2\end{array}$

$\begin{array}{llll}4.9 & 5 & 1.2 & 1\end{array}$

$\begin{array}{llll}2.3 & 3 & 0.7 & 2\end{array}$

$\mathrm{X}$ - mean, $\mathrm{Me}$ - median, $\mathrm{Sd}$ - standard deviation, $\mathrm{Qr}$ - quartile range

When taking into account particular conditions for creating exploratory innovation, it should be stated that entrepreneurs most often indicated the purchase of licenses (4.9), leadership in organization (4.3) and ensuring their own financial capital (4.2). The fewest respondents indicated financing activities dedicated to creation of innovations from external funds (2.4) and employee training. As far as the innovative exploitation is concerned, the survey revealed that the most important were: ensuring own financial capital (4.8), employee training, attending fairs and direct meetings with customers (4.0). The lowest percentage of responses in this respect concerned the purchase of a license/patent (2.3), leadership in organization (2.9) and financing activities from external sources. A more detailed look at the structure of responses shows that quite the respondents' opinions were quite diverse in the case of innovative exploitation, including in particular activities related to the purchase of licenses, provision of external infrastructure and financial capital, and provision of training for employees $(Q r=2)$. Simultaneously, minor differentials were observed in the case of responses concerning the innovative exploration. Moreover, it is worth noting that half of the respondents believed that the most important factor conditioning innovative exploration is the purchase of patents and licenses ( $\mathrm{Me}=5)$, while as regards exploitation innovation it was the provision of financial capital ( $\mathrm{Me}=5$ ).

Despite the differences in terms of particular drivers, the study reveals that in $58 \%$ of the surveyed companies the activities related to the creation of innovative exploration and exploitation were treated as complementary and simultaneous. On the other hand, over $40 \%$ of respondents perceived them as mutually exclusive. Therefore, at a further stage of the research it was justified to analyze the stochastic relationships between particular startup groups (see Table 2).

Table 2

Stochastic relationships - drivers of innovative ambidexterity -Mann-Whitney U test

\begin{tabular}{|c|c|c|c|}
\hline 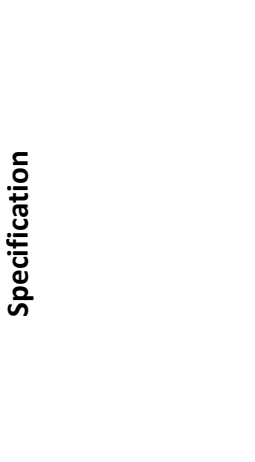 & 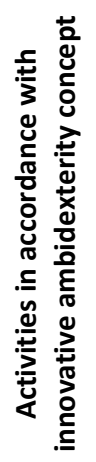 & 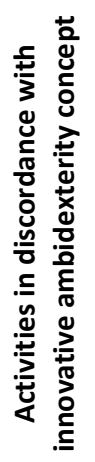 & $\begin{array}{l}\text { Lo } \\
\text { o } \\
\text { v } \\
\text { a }\end{array}$ \\
\hline \multirow{3}{*}{$\begin{array}{l}\text { ization } \\
\text { s, direct contacts }\end{array}$} & 20.32 & 16.69 & 0.01 \\
\hline & 19.29 & 15.28 & 0.00 \\
\hline & 18.32 & 32.12 & 0.02 \\
\hline \multirow[b]{3}{*}{ (incl. machinery } & 17.51 & 28.64 & 0.00 \\
\hline & 51.23 & 34.29 & 0.03 \\
\hline & 38.82 & 32.74 & 0.00 \\
\hline (incl. machinery & 23.43 & 38.62 & 0.02 \\
\hline & 31.23 & 29.83 & 0.00 \\
\hline
\end{tabular}

The stochastic dependencies presented in the table above reveal that employee training (20.32), leadership in organization (19.29), external capital (51.23), own infrastructure (38.82) as well as the purchase of patents and licenses (31.23) are more important for startups that treat exploration and exploitation activities as coherent in the process of creating innovations than for the group of young companies that do not regard them as consistent. Participation in trade fairs, direct contacts with customers (32.12), equity (28.64), external infrastructure (38.62) more strongly determine the process of creating innova- 
tions in startups which separate exploration and exploitation activities than in companies that are ambidextrous in their innovation efforts.

\section{DISCUSSION AND CONCLUSIONS}

Bearing in mind the above results, one can unequivocally indicate the conditions that most strongly determine the innovative ambidexterity of startups in Poland. In this context, it should be noted that the findings of this study, as well as the results of research by Almahendra and Ambos [1], Kim and Rhea [24] or Mueller, Paske and Rodil [19], highlight that startups are aware of the existing paradox of exploration and exploitation activities in terms of creating innovations. In this respect, almost two thirds of the surveyed companies declared that they were harmonizing those activities.

The results obtained in the course of the conducted research process point to some drivers of the innovative ambidexterity, which some researchers have already verified, e.g. leadership, the impact of financial equity and foreign capital on the creation of innovation, employee behavior [3, 19]. However, these studies mostly dealt with large multinational corporations, not startups. Moreover, unlike other research results $[14,17]$, the findings of this study indicate that the leadership and employees' participation in training programs, direct contacts with customers or their involvement in trade fairs are an important element of the coherence of exploration and exploitation activities being a part of creating innovation, but not the most important one. Therefore, the most important factors determining innovative ambidexterity in startups are: having access to external source of financing and to external infrastructure as well as the acquisition of a license/patent.

The above findings indicate that startups that create innovation and simultaneously reduce the tension between exploitation and exploration activities to a large extent rely on external sources when implementing their innovation processes. This conclusion is not surprising, as the creation of innovation requires the organization to involve multiple resources which young companies do not have in their early stages of development. Therefore, such resources need to be provided from the external environment. In this context, it is also worth noting that other drivers that are dependent on startups are important for the process of innovative ambidexterity and must be secured by the owners of innovative startups. Thus, leadership in the organization, the participation of employees in training programs and in direct contacts with customers, or their attendance at fairs can enhance innovative culture in the organization and, consequently, contribute to the effective use of external resources in the process of innovative ambidexterity.

The above conclusions should be treated only as practical recommendations as, despite the unrepresentative character of this study, the interviewees' responses are burdened with high subjectivity and the complex theoretical constructs were examined using few selected dimensions. Therefore, there is no doubt that these studies need to be continued. The studies obviously require follow-up including quantitative analyses carried out on a bigger sample. Despite this imperfection the most important drivers of innovative ambidexterity of Polish startups have been diagnosed. Therefore, the results may be useful in creating and developing start-ups in Poland.

\section{ACKNOWLEDGEMENT}

The project is finance dwithin the frame work of the program of the Minister of Science and Higher Education under the name "Regional Excellence Initiative" in the years 2019-2022, project number 001/RID/2018/19, the amount of financing PLN 10,684,000.00.

\section{REFERENCES}

[1] Almahendra R., Ambos, B.: Exploration and exploitation: a 20-year review of evolution and reconceptualisation. International Journal of Innovation Management, vol. 19(01), 2015.

[2] Andriopoulos C., Lewis M. W.: Exploitation-exploration tensions and organizational ambidexterity: Managing paradoxes of innovation. Organization science, vol. 20(4), pp. 696-717, 2009.

[3] Birkinshaw J., Gupta K.: Clarifying the distinctive contribution of ambidexterity to the field of organization studies. Academy of Management Perspectives, vol. 27(4), pp. 287298, 2013.

[4] Blank S., Dorf B.: The startup owner's manual: The step-bystep guide for building a great company. BookBaby, 2012.

[5] Blank S., Euchner J.: The Genesis and Future of Lean Startup: An Interview with Steve Blank. Research-Technology Management, vol. 61(5), pp. 15-21, 2018.

[6] Brem A.: Creativity and routine: conceptual considerations on managing organisational ambidexterity in entrepreneurial ventures. International Journal of Entrepreneurship and Innovation Management, vol. 21(3), pp. 261-273, 2017.

[7] Chen M., Yang Z., Dou W., Wang F.: Flying or dying? Organizational change, customer participation, and innovation ambidexterity in emerging economies. Asia Pacific Journal of Management, vol. 35(1), pp. 97-119, 2018.

[8] Coccia M.: Radical Innovations as Drivers of Breakthroughs: Characteristics and Properties of the Management of Technology Leading to Superior Organizational Performance in the Discovery Process of R\&D Labs. Technology Analysis \& Strategic Management, vol. 28 (4), pp. 381-395, 2016,

[9] Performance. Creativity and innovation management, vol.24(3), pp. 359-372, 2015.

[10] Felício J.A., Caldeirinha V., Dutra A.: Ambidextrous capacity in small and medium-sized enterprises. Journal of Business Research, vol. 101, pp. 607-614, 2019.

[11] Gilbert D.H, Smith A., Sutherland F.: Osmotic strategy: Innovating at the core to inspire at the edges. Organizational Dynamics, vol. 44.3, pp. 217-225, 2015.

[12] Goel S., Jones R. J.: Entrepreneurial exploration and exploitation in family business: A systematic review and future directions. Family Business Review, vol. 29(1), pp. 94-120, 2016.

[13] Guisado-González M., González-Blanco J., Coca-Pérez J.L.: Analyzing the relationship between exploration, exploitation and organizational innovation. Journal of Knowledge Management, 21(5), pp. 1142-1162, 2017. 
[14] Jansen J. J., Kostopoulos K.C., Mihalache O.R., Papalexandris A.: A socio-psychological perspective on team ambidexterity: The contingency role of supportive leadership behaviours. Journal of Management Studies, vol. 53(6), pp. 939-965, 2016.

[15] Jen Huang C., Ju Li C.: Exploration for the relationship between innovation, IT and performance. Journal of Intellectual Capital, vol. 6(2), pp. 237-252, 2005,

[16] Li D., Lin J., Cui W., Qian Y.: The trade-off between knowledge exploration and exploitation in technological innovation. Journal of Knowledge Management, vol. 22(4), pp. 781-801, 2018.

[17] Li Y., Vanhaverbeke W., Schoenmakers W.: Exploration and exploitation in innovation: Reframing the interpretation. Creativity and innovation management, vol. 17(2), pp. 107-126, 2008.

[18] March James G.: Exploration and exploitation in organizational learning. "Organization science, vol. 2(1) pp. 71-87, 1991.

[19] Mueller S., Volery T., von Siemens B.: What do entrepreneurs actually do? An observational study of entrepreneurs' everyday behavior in the start-up and growth stages. Entrepreneurship Theory and Practice, vol. 36(5), pp. 995-1017, 2012.

[20] Müller S. D., Påske N., Rodil L.: Managing Ambidexterity in Startups Pursuing Digital Innovation. Communications of the Association for Information Systems, vol. 44, pp. 273298, 2019.

[21] Perlow L.A., Okhuysen G.A., Repenning, N.P.: The speed trap: Exploring the relationship between decision making and temporal context. Academy of Management journal, vol. 45(5), pp. 931-955, 2002.

[22] Piao M.: A long life after exploitation and exploration. European journal of innovation management, vol. 17(2), pp. 209-228, 2014.

[23] Reis E.: The lean startup. New York: Crown Business, 2012.

\section{Jarosław Korpysa}

ORCID ID: 0000-0002-2400-3308

University of Szczecin

Faculty of Economics, Finance and Management

Institute of Management

Department of Support Decision's Methods

and Cognitive Neuroscience

ul. Mickiewicza 64, 71-101 Szczecin, Poland

e-mail: Jaroslaw.Korpysa@usz.edu.pl
[24] Rhee M., Kim T. 2016.: Exploration and exploitation. in M. Augier, D.J. Teece, The Palgrave encyclopedia of strategic management. Palgrave Macmillan, London, 2016 https://doi.org/10.1057/978-1-349-94848-2_388-1.

[25] Sariol A.M., Abebe M.A.: The influence of CEO power on explorative and exploitative organizational innovation. Journal of Business Research, 73, pp. 38-45, vol. 2017.

[26] Schreuders J., Legesse A.: Organizational ambidexterity: How small technology firms balance innovation and support. Technology Innovation Management Review, vol. 2(2), pp. 17-21, 2012.

[27] Sipe L.J.: How do senior managers influence experience innovation? Insights from a hospitality marketplace. International Journal of Hospitality Management, vol. 54, pp. 7583, 2012.

[28] Skala A.: The Startup as a Result of Innovative Entrepreneurship. In: Digital Startups in Transition Economies. Palgrave Pivot, Cham, 2019, pp. 1-40.

[29] Smith W.K., Lewis M.W.: Toward a theory of paradox: A dynamic equilibrium model of organizing. Academy of Management Review, vol. 36, pp. 381-403, 2011,

[30] Still K.: Accelerating research innovation by adopting the lean startup paradigm. Technology Innovation Management Review, vol. 7(5), pp. 32-43, 2017,

[31] Wasserman N.: The founder's dilemmas: Anticipating and avoiding the pitfalls that can sink a startup. Princeton University Press, 2012.

[32] Zakrzewska-Bielawska A.: Strategie rozwoju przedsiębiorstw: nowe spojrzenie. Polskie Wydawnictwo Ekonomiczne, Warszawa, 2018.

[33] Zakrzewska-Bielawska A.: "Struktury organizacyjne sprzyjające odnowie organizacyjnej przedsiębiorstw: ambidextrous approach". Management Forum., vol. 3. No. 1, pp. 105-111, 2015. 